\title{
Management of traumatic intracranial haematoma
}

\author{
G TEASDALE，S GALBRAITH， LILIAN MURRAY，P WARD，D GENTLEMAN， MARY McKEAN
}

\begin{abstract}
Deciding which head-injured patients should be transferred to a neurosurgical unit can be difficult. Traditional criteria emphasise the development of deteriorating responsiveness but lead to delayed diagnosis and to avoidable mortality and morbidity. To discover if a more liberal admission policy improved results a study was conducted analysing data collected prospectively from 683 patients who had a traumatic intracranial haematoma evacuated in the Glasgow neurosurgical unit between 1974 and 1980 . In the first four years, before the change in policy, mortality was $38 \%$ but decreased to $29 \%$ afterwards. This reflected a reduction in the proportion of patients who talked after injury but who deteriorated into coma before operation-that is, $31 \%$ before the change in policy, $16 \%$ afterwards.

If the potential benefits of CT scanning in the management of head injuries are to be realised patients must be scanned sooner than in the past. This will usually mean that more patients should go to a neurosurgical unit and that simple criteria for transfer should be established.
\end{abstract}

\section{Introduction}

Reports from centres in which most head-injured patients are admitted directly to neurosurgical care show clearly that the earlier a patient with a traumatic haematoma undergoes evacuation of clot the better is the patient's outcome. ${ }^{2}$ Yet head-injured patients throughout most of Britain are admitted initially to a primary surgical ward, and only $5 \%$ are subsequently transferred to a neurosurgical unit. ${ }^{3}$ Unfortunately, according to several studies the criteria widely used to select patients for transfer lead to avoidable mortality and morbidity in those with a traumatic intracranial haematoma. ${ }^{4-7}$ The reason for this is that it has been customary to suspect that a patient has a significant traumatic intracranial haematoma only after responsiveness deteriorates or if he fails to improve after several days; this leads to delayed diagnosis, so that by the time the clot is evacuated many such patients have already sustained irreversible secondary brain damage. ${ }^{4}$

There are several reasons for restricting severely the number of head-injured patients admitted to neurosurgical units. One is the availability of neurosurgical beds in relation to the total number of head-injured patients. In the past another reason was that the appropriate investigation-that is, angiography-was difficult, invasive, and potentially dangerous and therefore justified only in those patients most obviously suffering from an intracranial complication. The introduction of CT scanning has made the diagnosis of an intracranial haematoma simpler and safer and has shown that a haematoma may be present for some time before clinical signs develop. Scanning can therefore be

\footnotetext{
Department of Neurosurgery, Institute of Neurological Sciences, Southern General Hospital, Glasgow G51 4TF

G TEASDALE, FRCSED, FRCSGLASG, professor in neurosurgery

S GALBRAITH, MD, FRCS, consultant neurosurgeon

LILIAN MURRAY, MSC, MPS, statistician

$P$ WARD, FRCS, research assistant

D GENTLEMAN, FRCS, research assistant

MARY MCKEAN, MB, CHB, research assistant
}

justified at a stage that previously would not have been considered to merit angiography. Unfortunately, reports ${ }^{8}{ }^{9}$ show that the introduction of CT scanning by itself does not lead to improved results so long as patients are still selected by the traditional criteria.

In an effort to use the potential of CT scanning to achieve early diagnosis and thus reduce delays, we proposed that neurosurgical units should be more ready to accept headinjured patients and should investigate those who were considered to be at risk of having a haematoma, even though they had not (at that time) deteriorated. ${ }^{10}$ Such patients include those in coma or with neurological signs or persisting confusion, particularly when any of these features is associated with a skull fracture. ${ }^{11}$ The Glasgow neurosurgical unit began to apply this policy at the end of 1977. To discover how this influenced the management and outcome of patients with a traumatic haematoma we have compared the results in two periods: before and after the change in policy. CT scanning was available in Glasgow throughout both periods.

\section{Patients and methods}

We prospectively collected data about patients who had a traumatic intracranial haematoma evacuated in the Glasgow neurosurgical unit between January 1974 and December 1980. Only haematomas requiring craniotomy within two weeks of injury were included. Patients with contusions or small haematomas treated conservatively were excluded, as were those with a chronic subdural collection of fluid. Haematomas were classified as extradural or intradural; patients with both were regarded as having an intradural clot." ${ }^{11}$ Clinical responsiveness was assessed by the Glasgow Coma Scale, and coma was defined as no eye opening with no comprehensible verbal response and not obeying commands. ${ }^{12}$ Pupil reactivity was also recorded. A patient's best level of responsiveness before the onset of any subsequent deterioration was taken as an index of the extent of recovery from any brain damage sustained at the time of injury. The extent of deterioration was indicated by comparing this with the patient's state immediately before operation. Outcome was assessed six months after injury according to the Glasgow Outcome Scale. ${ }^{13}$

\section{Results}

Numbers of patients-During the four years 1974 to 1977 the numbers of operations for traumatic intracranial haematoma were 86 , 77,64 , and 78 , respectively ( 305 in all); in the next three years the numbers were 115,159 , and 104 ( 378 patients in all). The yearly rate increased from an average of 76 cases in the first period to 126 after $1978(p<0.001)$, but the types of haematoma evacuated and the patients' ages were similar in the two periods (table I).

Responsiveness before deterioration (table I)-Similar proportions of the two series of patients recovered sufficiently from the initial effects of the injury to be able to talk at some stage before operation. Conversely, similar proportions had persisting brain damage from the time of injury and did not talk afterwards. The proportion of patients whose pupils were unreacting from when they were first seen was also similar in the two periods $(8 \%$ in $1974-7 ; 11 \%$ in 1978-80).

Responsiveness before operation (table II) - The proportion of patients in coma immediately before operation was significantly lower in $1978-80$ than in $1974-7\left(\chi^{2}=16.8 ; 1 \mathrm{df} ; \mathrm{p}<0.001\right)$. This was because fewer patients who had talked after injury subsequently deteriorated into coma (33\% of patients in $1978-80$ compared with $52 \%$ before). Similarly, fewer patients developed non-reacting pupils in the second period (14\% in $1978-80$ and $30 \%$ before).

Outcome (table III)-An unfavourable outcome (death, vegetative stage, or survival with severe disability) was less frequent after 1977 
$(40 \%)$ than before $(51 \%)$. Mortality was reduced with both types of haematoma: in patients with an extradural haematoma mortality fell from $25 \%$ to $19 \%$, and in those with an intradural lesion the fall was from $47 \%$ to $35 \%$. Of the 181 patients who had talked after injury during 1974-7, $47(26 \%)$ deteriorated into coma and died; these accounted for $40 \%$ of all deaths in that period. In 1978-80 a total of 211 patients had talked, of whom only $25(12 \%)$ deteriorated into coma and died; these patients accounted for $23 \%$ of deaths in the second period. In both periods patients in coma before operation had a higher mortality $(1974-7,53 \% ; 1978-80,46 \%)$ than those with a better level of responsiveness $(1974-7,10 \% ; 1978-80,12 \%)$.

TABLE I-Details of patients studied

\begin{tabular}{|c|c|c|}
\hline & \multicolumn{2}{|c|}{ No $\left({ }^{\prime \prime}(1)\right.$ of patients } \\
\hline & $1974-7(n=305)$ & $1978-80(n=378)$ \\
\hline Age (years) $\left\{\begin{array}{r}39 \\
40\end{array}\right.$ & $\begin{array}{l}132(43) \\
173(57)\end{array}$ & $\begin{array}{l}145(38) \\
233(62)\end{array}$ \\
\hline $\begin{array}{l}\text { Extradural clot } \\
\text { Intradural lesion only }\end{array}$ & $\begin{array}{l}119(39) \\
186(61)\end{array}$ & $\begin{array}{l}127(34) \\
251(66)\end{array}$ \\
\hline $\begin{array}{l}\text { Talked } \\
\text { Never talkєd* }\end{array}$ & $\begin{array}{l}181(59) \\
123(41)\end{array}$ & $\begin{array}{l}211(56) \\
167(44)\end{array}$ \\
\hline
\end{tabular}

* In one case in 1974-7 it was not known if the patient had talked.

TABLE II-Responsiveness before operation

\begin{tabular}{lcc}
\hline & \multicolumn{2}{c}{ No (“".) of patients* } \\
\cline { 2 - 3 } & $1974-7(\mathrm{n}=304)$ & $1978-80(\mathrm{n}=377)$ \\
\hline Not in coma & $104(34)$ & $188(50)$ \\
In coma $\left\{\begin{array}{l}\text { Had talked } \\
\text { Never talked }\end{array}\right.$ & $106(31)$ & $62(16)$ \\
& & $127(34)$ \\
\hline
\end{tabular}

* Information missing on one patient in each period. Reduction in proportion of patients in coma was significant
$\left(\chi^{2}=16.8 ; 1 \mathrm{df} ; \mathrm{p}<0.001\right)$.

TABLE III-Outcome six months after evacuation of traumatic intracranial haematoma

\begin{tabular}{|c|c|c|}
\hline & \multicolumn{2}{|c|}{ No $("$ ".) of patients } \\
\hline & $1974-7(n=305)$ & $1978-80(n=378)$ \\
\hline $\begin{array}{l}\text { Dead } \\
\text { Vegetative }\end{array}$ & $\left.\begin{array}{r}116 \\
1\end{array}\right\}(38)$ & $\left.\begin{array}{r}107 \\
4\end{array}\right\}(29)$ \\
\hline Severe disability & $40 \quad(13)$ & $43 \quad(11)$ \\
\hline $\begin{array}{l}\text { Moderate disability } \\
\text { Good recovery } \\
\text { Unknown but out } \\
\text { of hospital }\end{array}$ & $\left.\begin{array}{r}39 \\
101 \\
8\end{array}\right\}(49)$ & $\left.\begin{array}{r}55 \\
138 \\
31\end{array}\right\}(60)$ \\
\hline
\end{tabular}

Reduction in proportion of patients with poor outcome (dead, vegetative, or severely disabled $)$ was significant $\left(\varkappa^{2}=8 \cdot 2 ; 1 \mathrm{df}\right.$;
p. 0.005$)$.

\section{Discussion}

CT scanning is a highly reliable means of detecting a traumatic intracranial haematoma. It provides an exact location so that surgery may be planned precisely, and it has reduced the need for emergency burr holes. ${ }^{8}$ But diagnosis must be earlier as well as more anatomically accurate in order to ensure that as many clots as possible are evacuated before irreversible secondary brain damage develops. Baker emphasised that most scanners in Britain are available easily only to neurosurgeons, whereas most head-injured patients are in primary surgical wards and accident departments. ${ }^{14}$ Hence if intracranial clots are to be diagnosed sooner there must be a change in the criteria used to select patients for transfer and investigation.

The introduction of a more liberal transfer policy in the west of Scotland increased the total number of patients admitted to a neurosurgical unit from an average of 223 a year at the beginning of the study ${ }^{3}$ to 492 a year in $1979-80$. The mortality of patients with an intracranial haematoma fell from $38 \%$ to $29 \%$.
The increase in the number of patients with a clot that neededto be evacuated was unexpected, and this alone might have influenced the results.

In practice, the additional patients in the second periog included both severely and mildly injured people so that overalp the two series were closely similar with respect to importan prognostic factors such as age, the type of haematoma, and theproportion of patients with severe primary brain damage. The presence of brain damage that is severe from the start is reflected in the patient being in coma from the time of injury, and it if these patients who now account for the major proportion ofmortality and morbidity in patients transferred to the neuro surgical unit. In the first period many such patients probabl: remained in the primary surgical ward and either died of survived with disability. Indeed, in Merseyside, where only $1.2 \%$ of patients admitted for head injuries are transferred to the regional surgical unit, deaths from an intracranial haematomf occur as often in general hospitals as in the regional unit. $\delta$ Studies are in progress to establish if the change in admission? policy in Glasgow has reduced deaths in the general hospitals irifo our region.

Although more mildly injured patients were admitted duringి the second period, the improved outcome cannot be explaineळ by unnecessary operations on patients with a small haematom; who would have recovered without surgery. CT scanning was available in both periods and neurosurgeons in Glasgow haves made a point of adopting an expectant policy in the managemen? of these kinds of haematomas..$^{15}$ During the second period of the study more than 100 such haematomas were managed withou民 operation. The most likely reason for the improved results in the्ठ second series was that a smaller proportion of patients hadB deteriorated into coma before operation; this indicates that fewer patients had developed irreversible secondary brain damage.

Several different methods are advocated that aim to minimise delay in the detection of a traumatic intracranial haematoma. In North America and in a few British centres the view is that as many head-injured patients as possible, including all those with a mild injury, should be managed by neurosurgeons. Anotherō view is that scanners should be available in general hospitals sofँ that haematomas could be detected there ${ }^{16}$; the patient migh $\mathbb{D}$ then be operated on in the general hospital or sent to a regionaf: neurosurgical centre. Both approaches are expensive in resources; moreover, without an alteration in the clinicab criteria for investigation neither method would guarantee reduced delay and improved results. Investigation outside neurosurgical unit might even increase delay. The best methods would be to establish simple clinical criteria for identifying before deterioration which head-injured patients have a high 3 . risk of haematoma so that these could be transferred for scanningo and possible operation.

Even after the change in policy only $7 \%$ of head-injured patients admitted to hospital in the west of Scotland were trans- - ? ferred to the neurosurgical unit. The increase in admissions to $N$ the neurosurgical unit was feasible because patients were $>$ returned rapidly to the referring unit after a significant intracranial lesion had been excluded and also because a few addi- $\tilde{O}$ tional beds became available. Avoidable mortality and morbidityన్ట్ are still occurring and their elimination may require the $\mathcal{E}_{\sigma}$ investigation of even more patients-possibly at least $10 \%$ of those presently admitted to hospital. Additional neurosurgicaf? facilities for the investigation of head injuries might be provided@ from the resources that would be released by a reduction in the total number of admissions for head injury. This could be achieved if fewer mildly head-injured patients were admitted for observation than at present. Most of these patients have a $\frac{?}{\mathbb{D}}$ negligible risk of haematoma, and studies in Nottingham show $\frac{0}{\sigma}$ that many can safely be discharged. ${ }^{17}$

It is essential to break away from the tradition that a traumatico intracranial haematoma is diagnosed only after there has been? progressive neurological deterioration. It is also clear that moreo head-injured patients should go to a neurosurgical unit than? occurs in most places in Britain and that they should go there 
sooner. We now advocate that a recently head-injured patient should have a CT scan if he has either altered consciousness or other neurological signs or symptoms that do not improve after initial assessment and resuscitation. When there is a skull fracture the indications for scanning are increased; even by itself a fracture probably provides an adequate reason.

\section{References}

' Mendelow AD, Karmi MZ, Paul KS, Fuller GAG, Gillingham FJ. Extradural haematoma: effect of delayed treatment. $\mathrm{Br} \mathrm{Med} \mathcal{F} 1979$; : 1240-2

2 Seelig JM, Becker DP, Miller JD, et al. Traumatic acute subdural hematoma. Major mortality reduction in comatose patients treated within four hours. $N$ Engl 7 Med $1981 ; 304: 1511-8$.

3 Jennett B, Murray A, Carlin J, McKean M, MacMillan R, Strang I. Head injuries in three Scottish neurosurgical units. Br Med f 1979;ii:955-8.

4 Galbraith S. Misdiagnosis and delayed diagnosis in traumatic intracranial haematoma. Br Med f 1976; i:1438-9.

5 Rose J, Valtonen $S$, Jennett B. Avoidable factors contributing to death after head injury. $\mathrm{Br}$ Med f 1977;ii:615-8.

6 Jennett B, Carlin J. Preventable mortality and morbidity after head injury. Injury $1978 ; 10: 31-9$.

Jeffreys RV, Jones JJ. Avoidable factors contributing to the death of head injury patients in general hospitals in Mersey region. Lancet 1981 ;ii: 459-61.

${ }^{8}$ Ambrose J, Gooding MR, Uttley D. EMI scan in the management of head injuries. Lancet $1976 ; \mathrm{i}: 847-8$.

9 Jeffreys RV, Lozada L. The use of the CAT scan in the management of patients with head injury transferred to the regional neurosurgical unit. Injury 1982;13:370-4.

10 Teasdale G, Galbraith S. Extradural haematoma: effect of delayed treatment. Br Med f 1979;i:1793.

11 Teasdale G, Galbraith S. Acute traumatic intracranial haematomas. In Krayenbuhl H, Maspes PE, Sweet WH, eds. Progress in neurological surgery. Vol 10. Basle: Karger, $1981: 252-90$.

12 Teasdale G, Jennett B. Assessment and prognosis of coma after head injury. Acta Neurochir (Wien) 1976;34:45-55.

13 Jennett $B$, Bond $M$. Assessment of outcome after severe brain damage. Lancet $1974 ;$ i:480-4.

14 Baker IA. Availability of computed tomography for the management of head injuries in England and Wales. Br Med 7 1982;285:487-9.

15 Galbraith S, Teasdale G. Predicting the need for operation in the patient with an occult traumatic intracranial hematoma. $\mathcal{f}$ Neurosurg $1981 ; 55$ : 75-81.

16 Bartlett JR, Neil-Dwyer G. Clinical study of the EMI scanner: implications for provision of neuroradiological services. $\mathrm{Br}$ Med $\mathcal{f} 1978$;ii: 813-5.

17 Weston PAM. Admission policy for patients following head injury. $\mathrm{Br} \mathcal{F}$ Surg $1981 ; 68: 633-64$.

(Accepted 8 October 1982)

\title{
Converting-enzyme inhibitor enalapril (MK421) in treatment of hypertension with renal artery stenosis
}

\author{
G P HODSMAN, J J BROWN, D L DAVIES, R FRASER, A F LEVER, J J MORTON, \\ G D MURRAY, J I S ROBERTSON
}

\begin{abstract}
Enalapril maleate (MK421), a new inhibitor of angiotensin converting enzyme, in single daily doses of $1.25-40 \mathrm{mg}$ was assessed in five patients with hypertension and renal artery stenosis. Only small falls in plasma angiotensin II concentrations were seen at doses less than $10 \mathrm{mg}$; even with 10 and $20 \mathrm{mg}$, angiotensin II concentrations had risen again 24 hours from the last dose. During long-term treatment with $10-40 \mathrm{mg}$ daily all patients achieved good blood-pressure control. No significant changes of body sodium or potassium values were seen. The drug was well tolerated with no serious side effects.

These findings are evidence of the efficacy and acceptability of enalapril in the medical management of hypertension with renal artery stenosis.
\end{abstract}

MRC Blood Pressure Unit, Western Infirmary, Glasgow G11 6NT G P HODSMAN, MRCP, medical registrar

J J BROWN, FRCP, consultant physician

R FRASER, PHD, scientist

A F LEVER, FRCP, consultant physician

J J MORTON, PHD, scientist

J I S ROBERTSON, FRCP, consultant physician

Gardiner Institute of Medicine, Western Infirmary, Glasgow G11 6NT

D L DAVIES, FRCP, senior lecturer in medicine

Department of Statistics, Glasgow University, Glasgow G12 $80 Q$ G D MURRAY, PHD, lecturer in statistics

\section{Introduction}

We have reported ${ }^{1}$ the use preoperatively of the convertingenzyme inhibitor captopril in the treatment of hypertension associated with unilateral renal artery stenosis. Long-term captopril promised well as a predictor of the blood-pressure response to operation, although this requires further study. We have also reported that oral captopril in a dose of $150 \mathrm{mg}$ three times daily produces sustained suppression of the plasma angiotensin II concentration throughout 24 hours. ${ }^{2}$ Captopril, however, has been associated with several toxic effects which may be attributable to the sulphydryl group in its molecule. ${ }^{3}$ Although the use of lower doses of captopril may avoid at least some of these unwanted effects, it appears important to consider alternative converting-enzyme inhibitors. Enalapril maleate (MK421), ${ }^{4}$ an orally active converting-enzyme inhibitor devoid of a sulphydryl group, may permit long-term inhibition of angiotensin II formation without incurring the side effects seen with captopril. We report preliminary results of the use of longterm enalapril in five patients with hypertension and renal artery stenosis. Particular attention was paid to the magnitude and duration of the reduction in plasma angiotensin II concentrations.

\section{Patients and methods}

Five patients (two women) aged 38-56 years gave informed consent to the study, which was approved by the hospital's ethical supervisory committee. All patients had unilateral renal artery stenosis shown by intravenous pyelography, renal arteriography, isotope nephrography, ${ }^{5}$ bilateral renal vein renin measurements, and ureteric catheter studies. ${ }^{16}$ Four had radiological evidence of atheroma and one fibromuscular hyperplasia. All had normal serum electrolyte values and renal 